\title{
Organizational Change: Importance of Leadership Style and Training
}

\author{
Sinem Somunoğlu İkinci ${ }^{1, *}$ \\ ${ }^{1}$ Health Services Vocational School, Uludağ University, Bursa, Turkey \\ *Correspondence: Health Services Vocational School, Uludağ University, Görükle Campus, Nilüfer, Bursa, Turkey. \\ Tel: 90-224-294-2493. E-mail: ssomunoglu@yahoo.com, ssomunoglu@uludag.edu.tr
}

Received: October 31, 2013

Accepted: November 21, $2013 \quad$ Online Published: August 12, 2014

doi:10.5430/mos.v1n2p122

URL: http://dx.doi.org/10.5430/mos.v1n2p122

\begin{abstract}
In parallel with the rapid transformation of the world, there emerged some changes in both the approaches to leadership and the information obtained. When the approaches to leadership are viewed, it is seen that previously it had been mostly addressed along with power, competence and it had been ascribed to the rulers of a country. The modern approaches to leadership today are represented by some attributes of the leaders such as having charisma, being able to create organizational change, performing change, creativity in their own fields, and being successful in an environment of uncertainty. Furthermore, it is a crucial point that the human resources are required to be used more effectively and efficiently in order to keep up with the developments, transformations experienced and to have competitive power. Therefore, in order to improve the performance of human resources, to increase the level of knowledge and skill and to adapt to organizational change, due attention should be given to training facilities and measures to increase the efficacy of the training should be introduced. This study deals with the concepts of organizational change, leadership, training, the importance of training and leadership during the course of organizational change, and their possible effects.
\end{abstract}

Keywords: organization; organizational change; leadership; transformational leader

\section{Introduction}

It is stated that change is an important reality of our age and the actuality of the matter is emphasized through the saying "the only thing that does not change is change itself". In the face of constant change, it is said that there is no way but to change in order to adapt to the change. Organizations are dynamic and open systems that are constantly in transaction and communication with their environments (Töremen, 2002). When viewed from this perspective, it is seen that it becomes highly important for an organization to adapt to the changes in its course to maintain its existence (Tunçer, 2011). It has been notified that to have a capacity and capability to change is important and influential for organizations in the course of adapting to and making a change. For this, they should possess some necessary conditions such as a desire for change, readiness for a change, and having the necessary resources to make the change. Moreover, the contribution of grasping the philosophy of change and having a sufficient amount of political support should not be ignored (Töremen, 2002). Another significant point is the fact that unchangeability and stability lead to organizational resolution and entropy when we consider the need of organizations for a constant interaction with their environment as living systems (Saylı \& Tüfekçi, 2008).

In order for an organization to adapt to the changes around, it is necessary for it to adopt an effective leadership approach besides being organized and making organizational arrangements (Tunçer, 2011). The underlying reason for this is the perception that gaining changeable characteristics and making these characteristics sustainable are significant leadership problems. It is reported that if the administrators with strong leadership qualifications do not have a word in managing organizations, the possibility for that organization to renovate itself and to adapt to changes will be reduced (Saylı \& Tüfekçi, 2008). The characteristics of leadership needed during the course of organizational change and change period depend on the objectives, field of activity, structure, and the environment of the organizations (Tunçer, 2011). When the literature is reviewed, the type of leader needed is stressed to be a transformational type of leader, especially to make the change and transformations in an organization, to reconstruct their organizations and to trigger their organizations. Besides an effective leadership, there is a need for information management and accurate information which contributes into the effective decision making processes of the leader in order to transform the organization successfully. For this, it is of great importance for the organizations to pay attention 
to training and development activities, to impose an understanding of life-long learning on the workers, and to enable the sustainability of education (Atak \& Atik, 2007).

In this study, we will mention about the organizational change process and its aims which is one of the contemporary issues of our day and we will include the potential benefits of sustainable training with a transformational leader which is a type of leadership required for the organizational change process and his/her characteristics.

\section{The Concept of Organizational Change and Its Aims}

Today, there are significant factors that compel the organizations to change. So, it becomes inevitable for the organizations to change. This leads organizations to attempt to change, sometimes consciously and systematically and sometimes unconsciously. The underlying reason for this is that the changes in the surrounding of the organization have an influence on the organization and distort its balance. At this point, the application of continuous development and improvement programs becomes important for the organization to struggle with the competitive conditions, to obtain better results and to maintain its existence (Tunçer, 2011). It is thought that only in this way it will be possible for the organization to adapt to its environment which has a dynamic and constantly changing nature (Toker, 2007).

The concept of change is considered among the major characteristics of social, political and economic systems and the success of an organization to maintain its existence is explained by its ability to change. It is seen that there are various definitions of change in literature (Saylı \& Tüfekçi, 2008). When these definitions are analysed, we see that essentially four points come to forefront: management of change, the need of change for expertise, nourishing change with information, and the necessity to monitor a planned process. While managing the change requires the effective practice of novel methods and systems in the organization and doing it systematically; the need of change for expertise points out that change is a phenomenon that requires experience and knowledge and there exists a capability to quickly adapt to changing conditions. Nourishing change with information involves all kinds of models, methods, and information forms to be used in practice; while its being a planned process means that change is a planned and specialization-required activity (Toker, 2007).

The definitions of organizational change are mostly described as the transformation of a system from one state to another, to experience differentiation, a transformation in the cultural, structural and technological fields of an organization, and the responses given to the environment (Saylı \& Tüfekçi, 2008). From another perspective, organizational change includes all the events and phenomena such as creativity, innovation, development, improvement etc. through the structural adaptation of the organizations to their environments (Töremen, 2002). In his study Rensis Likert emphasized the continuity of the change, stating that all the organizations experience either small or big changes in a way (Saylı \& Tüfekçi, 2008). As understood from the explanations, organizational change can be observed in three major fields: change in the human factor, change in the organizational structure, and change in technology. Change in human factor refers to radical changes in believes and behaviours, including the change in the knowledge, skills and attitudes of workers in correlation with newly-set management policies. Change in organizational structure implies redefinition and regulation of organizational roles and relations. In making changes in organizational structure, methods are used such as expanding or reducing audition, determining the decision making authority, selecting decentralised or central management type, regulating communication channels etc.. Change in technology involves changing the technology that an organization uses to increase the quality in production (Töremen, 2002).

The reason that leads organizations to change is the notion that the benefits of organizational change for an organization outweigh the resulting chaos and hazards in the organization. Discontents in an organization also have a great influence on taking the first steps to start change and to develop alternative ways. In this sense, it is possible that the need for an organizational change may emerge as stimulation from inside the organization, while it may also be produced out of the idea to adapt to changes in external environment. After all, for any organization which does not want to shut down and cease to exist, it is highly important to be at peace and compatible for the changes around it. When it is considered that in order to be modern organization, it is necessary to be sensitive to developments in the world and constantly renew itself, we can easily understand why organizations need to follow changes and innovations and why they adopt this aim (Turan, 2011).

When the literature is reviewed, it is seen that there are some primary aims of organizational change process which has a great importance for organizations (Töremen, 2002). Accordingly, it is seen that the major aim of organizational change is to increase efficacy and productivity while it is aimed to integrate the necessities of a work and the qualifications of the persons who do that work in order to do that work more effective and an organizational structure is 
desired in which the workers have the highest levels of satisfaction (Töremen, 2002; Turan, 2011). Apart from this, other aims of organizational change can be listed as to be ready for future, to establish relationships that depend on mutual trust between the workers in the organization, to improve communication, to develop suggestions to solve the problems encountered, to create synergy, to maintain the wholeness and continuity of an organization (Töremen, 2002). Furthermore, it is also possible to include in the aims of organizational change to meet the changing expectations of the consumers most efficiently and to produce a service that is in accordance with the developments in both the human rights and information technologies (Kocabaş, 2012).

\section{Organizational Change Process and Leadership}

\subsection{Organizational Change Process}

In parallel with the social, economic and technological developments in management science especially since 1970s, it is stated that the need for organizational change is called upon (Özgener \& Kıliç, 2009). The factors that necessitate the organizational change are covered under two main categories. The first of these is to find the ways to conduct something better and the other is to best meet the changing expectations of the internal and external environments (Olkun, 1995). It is stressed out that there are other reasons that push the organizations into change apart from the two above-mentioned classifications. Some of these reasons are the emergence of communication problems, an increase in organizational crisis and conflicts, a decrease in performance, a change in the organizational culture, growing competitive environment and globalisation (Töremen, 2002).

Kurt Lewin, who is among the first people to examine the organizational change process, points out that there are three main stages of change. These stages are referred as behaviour analysis- to start change, transition stage - the maintenance and refreeze stage- the desired case. Behaviour Analysis is a stage in which information is collected about a new case, the expectations of the workers are found out and they are enlightened, the possible resistances are determined, and the convincing period is undergone. The leader's intuition and ability to take precautions becomes important to inspire confidence to the workers who are happy with the current situation and thus worry about the uncertainty that will come along with change. The transition stage includes considering the organization as whole, determining how the changes will affect the organization, sharing the potential results of the change, and the targeted structure with the workers. In this way, it will be possible for the workers to participate in the process and give their support. The refreeze stage includes the attempts to provide permanence as it is aimed to provide the continuance of the case achieved after change and to make the change continuous. Training and support activities are conducted to make the workers adopt the policies, rules and methods accompanying the new case and to make them behave in accordance with the procedures. The underlying reason for this is the impossibility of predicting the results always earlier during an organizational change process and the need arising for a better analysis of the organization to remove this uncertainty. This is accompanied by a need for a leader to transform the organization and it is of great importance that this leader should clearly and accurately express the necessary strategies, policies and applications (Sayli \& Tüfekçi, 2008).

\subsection{Leadership in the Organizational Change Process}

It is stated that each change leads to a transaction. Therefore, it is natural to experience some changes in an organization's aim and strategies, structure and technology for the tasks, its culture and habits and in human factor (Tunçer, 2011). In order for an organizational change to be successful, it is highly important that the organization workers adopt this change and believe that it will bring benefit. At this stage, it is stated that the mission of the leaders gains more and more importance. The leaders should find a compelling reason to change, should point a common goal to activate the workers, should use his/her convincing ability, should create an effective communication network, should support the workers and should share the achievements with them. In this way, leaders manage the organizational change and contribute into the learning process and development of the workers as he or she is always open to development and change (Töremen, 2002). The leaders also should plan the change well, should provide the training of the workers as part of the change, should prepare them for the change and should motivate the workers in line with the change (Saylı \& Tüfekçi, 2008).

When the traditional definitions of the leadership are reviewed, it is defined as all the characteristics related to the qualification, ability and experience to gather a group of people under certain goals and to activate them. It is reported that today the missions of the leaders are not only to influence people and activate a structure, but there are different leadership typologies. From this perspective, transformational leadership approach which stands out due to the change and developments in the management science catches attention and becomes more and more important for 
today's management theories and applications (Eraslan, 2014).

There are statements that imply the transformational leadership approach as the mostly adopted leadership approach especially in recent years that is successful in the organizational change process and in this way it is pointed that it will be possible for the workers to feel confidence in their leaders, to internalize him or her, and to go into action in the direction of the goals. In this leadership model, the leader's realization of the need for an organizational change, his/her establishment of a vision and institutionalization of the change are quite important features. Among the principles to be adopted by a transformational leader are matters such as a clear identification of the goals, creation of an encouraging environment for the workers, provision of individual support etc. (Eisenbach et al., 1999). It is pointed out that a transformational leader has influences in additional effort, efficacy and satisfaction and it is also stated that they are eager to perform organizational requisites since they think that the needs of the workers are met and they are represented well (Karip, 1998). It is also stated that a transformational leader has also such important characteristics as to be an example for the people around, to create incentives that inspire the workers, to provide intellectual stimulation, to provide individual support and to be charismatic (Eraslan, 2014). A transformational leader carries out works on such matters as determination of what the problems are in an organization, why the organization needs a change etc. and he/she plays an active role in the process to make fundamental changes in the political and cultural structure of the organization (Tichy \& Ulrich, 2008).

In literature, it is pointed out that there are several ways that a transformational leader should follow to allow for a successful organizational change. These are listed as to create a feeling of urgency, to provide a precise guidance, to determine a vision, to share the vision, to give the authority to the workers to act in line with the vision, to plan short term gains, to execute more changes by reinforcing the improvements and to institutionalize new approaches (Sayl1 \& Tüfekçi, 2008):

To create a feeling of urgency reflects the creation of a strong ground to manage the effort to change. Some workers understand the necessity of a change and unite their efforts to practice this by exhibiting a conscious organization. Therefore, the workers displaying such activities are referred as the champions of change. A transformational leader contributes into the creation of a confidence and communication environment by assembling these kind of workers and assessing the problems and opportunities of the organization.

To provide a precise guidance includes the activities to gather the people who are eager for a change and to encourage the group to work in a team and the guidance activities undertaken by a transformational leader contribute into the organizational change process.

To determine a vision is among the typical characteristics of a transformational leader and it is only possible when the leader, who can anticipate the future and provide innovations, adapts to the changing conditions and pioneers.

To share the vision includes a clear expression of the vision of a transformational leader and his or her sharing the excitement with the workers. In this way, it will be possible for the workers to commit themselves to the work with equal resolution.

To give authority to the workers to act in line with the vision makes the workers to act according to the vision and to have a shared goal and increases the motivation of the workers.

To plan short term gains is important to determine the awards and benefits of the organizational change for the workers and it helps to decrease the resistance of the workers and increases the tendency to embrace a change.

To execute more changes by reinforcing the improvements is important for a transformational leader to detect the possible outcomes of an organizational change and to monitor the change, to recruit people who can contribute into the vision and to allow for new ideas.

To institutionalize new approaches is important to prevent inactivity and loss of energy and excitement in the workers of the organization and it allows the institutionalisation of the changes.

According to another view apart from the importance of a transformational leader in the organizational change process, the key to change in an organization is the total quality method that adopts an effective leadership and participative management approach. To adopt this approach is accompanied with the facts that the continuity of the training and change is ensured, the communication is improved, the management believes in the change and the workers are motivated (Töremen, 2002). This is because total quality management has a perspective that considers human factor as an important resource, that grounds on participation, team work, and performing the work correctly at one sitting, and that sees education as a base for constant change and improvement (Toker, 2007). It is also stated that the approach of total quality management which is referred as "Kaizen" and described as "dedicating oneself to constant change" is 
influential in establishing the sustainability in education and adopting a learning organization structure. In this respect, it is believed that organizational change can be achieved through total quality management and a new organizational culture will be created while the workers of an organization will develop their personalities and improve professionally through continuity of education and the possible resistances will be overcome through making the workers believe in change (Töremen, 2002). In this way, it becomes possible for the workers to offer creative suggestions for the problems in the organization in an democratic environment (Lakomski, 2001).

\subsection{Training and Learning in the Organizational Change Process}

As well as the evaluation of the indicators of a successful organizational change through the outcomes based on the efficacy and performance of the organization, it is also important that it should cover the values of the organizational culture and major changes. In the process to evaluate the changed values and the applications through the new skills gained, it is also important to pay attention to organizational learning besides the organizational change. In order for an organizational change to be successful, there should be a change in the values and main goals of the workers as well and the workers should be eager to to learn new behaviours. From this perspective, training and learning have a great importance for the reconstruction process of the organization into a social organization (Töremen, 2002) and it contributes to create the desired behaviour changes in the workers. Training allows one to improve higher mental abilities and to update his/her knowledge, skills and behaviours by creating an awareness for his/her learning potential. This accelerates the adaption of the worker to his/her environment and organizational change process and it makes the need for continual training and learning indispensable for the workers (Genç and Eryaman, 2012). Furthermore, when we consider that an organizational change is always accompanied with new knowledge and processes, it becomes important to successfully implement continuing training in the course to decrease the workers' fear of these changes. It will not only be possible to overcome the fear of the workers for the uncertainty through the scheduled continuing training works in the organizational change process, it will also be possible for the workers to obtain knowledge, skills and abilities that will be needed in the future (Basim et al., 2012).

It is pointed out that the abilities of organizations to adapt to the changes around and to respond to organizational change originate from their characteristics of being learning organizations. The basic characteristic of workers in a learning organization is their ability to foresee the change beforehand, to embrace it and to achieve adaptation to it (Korkmaz, 2008). Being sensitive to respond to changes as necessitated by the nature of learning organizations results in a more significance of these characteristics especially during a course of change (Töremen, 2002). Because, learning organizations operate with a mechanism that renew themselves, interact with external environment, adopt openness principle, and always act on the basis of information. This causes organizations to have sensitive and adapting characteristics to changes (Öneren, 2008). Organizational change is referred as a wind of change accompanying globalisation and stressed as a driving force that increases the need of organizations for education and improvement and that makes the organizations to be a learning organization. What is important in the process of adaptation to organizational change is to stretch learning abilities of organizations to the whole organization, not only to individuals. In this way, both adaptations to changes will be possible and also a modern management practice that internalizes new information and innovations will be performed. Especially in recent years, in the process of maintaining their existence and adapting to changes, organizations accelerated their pace on the way to be learning organization, grasping the significance of information and learning (Atak \& Atik, 2007).

According to Senge and Kofman, another characteristic of a learning organization is its possession of a transformational leader that can think, question and take risks. Transformational leaders can trigger the organizational change process by enabling the transfer of thoughts, knowledge and learned things between the personnel in the organization and thus can contribute into the learning organization culture (Korkmaz, 2008). Therefore, it is stated that the need increases day by day for leaders who can coordinate and motivate workers, create a suitable learning environment by emphasizing the importance and application of information, manage information, trigger change, and set clear aims to undergo the organizational change process successfully (Erdil \& Keskin, 2004).

An increase in the ability of an organization to learn and its attention to training are important factors for the organization in their course to maintain its existence and to show an outstanding performance (Basim et al., 2012) and they facilitate the organization's adaptation to social, political and economic environments. It is stated that organizational learning also facilitates the systematic change of the organizational behaviour, shapes the organizational culture by creating cultural awareness and is one of the main processes to continue organizational change (Gizir, 2008). 


\section{Conclusion}

As a natural consequence of being an information society, we undergo a rapid change and the need for learning is emphasized in the course of adaptation to this change because it is possible for organizations to maintain their existence, to protect their competitiveness, and to meet the expectations of their society only by acting in accordance with the conditions of age and orientating to change. In this respect, it is inevitable for the organizations to be influenced by the changes in the environment around them. It is highly important to precisely identify the possible hindrances of the change and the need for an organizational change in order to be able to direct organizational change efforts and to establish appropriate strategies. Besides, it should not be ignored that there are positive effects of adoption of a learning organization structure that gives priority to continuing education approach and adoption of transformational leadership which is accepted to be an effective type of leadership in order for an organizational change process to be successful. Because a transformational leader should analyze well the environment around and the need for change, should plan for future, should perceptibly explain the goals of the organization for a sustainable change, should eliminate the hindrances of the change and prepare the organization and workers to the change, should support the workers, should adopt participative approach, should emphasize the importance of information and managing information, should create an environment of trust, should make the workers adopt the strategies related to organizational change through continuing training, should create appropriate environment for learning and increase the knowledge and develop the skills of the workers through trainings.

Another point to take into account is that it is important to act in a team, to include the workers in the decisions made, to provide opportunities for the workers to display their creativity and to share the enthusiasm of change. In this way, not only will it be easier to overcome the resistance against the change and the problems related to change, but also the capability to adapt to changes will increase.

Other remarkable variables in the organizational learning process are that the organization is taken as a whole and the transformational leader displays facilitating and motivating behaviours, is open to the innovations, improves the communication, attempts to re-arrange all the processes of the organization and displays behaviours in accordance with the learning organization model. In this way, it is thought that it will be possible for the organization to continue its achievements, maintain its existence, to compete and to meet the expectations of both the workers and the society. An organization with all these qualifications is believed to act consciously and systematically, to have a constant interaction with its environment, to maintain its existence, and to be successful in the process of organizational change.

\section{References}

Atak, M., \& Atik, İ. (2007). The significance of continuing education in organizations and its effects on creating a learning organization. Journal of Aviation and Space Technologies, 3(1), 63-70.

Basım, N., Varoğlu, K., \& Şeşen, H. (2012). Change and organizations. Retrieved 12th July, 2012 from staff.neu.edu.tr/.../...doc file

Eisenbach, R., Watson, K., \& Pillai, R. (1999). Transformational leadership in the context of organizational change. Journal of Organizational Change Management, 12(2), 80-89. http://dx.doi.org/10.1108/09534819910263631

Eraslan, L. (2004). A post-modern paradigm in leadership: transformational leadership. Journal of International Human Sciences, 1(1), 1-32.

Erdil, O., \& Keskin H. (2004). The Correlations between Competition Strategies and Company Performance, The Efficacy of performing Work Change, the efficacy of information system and the characteristics of organizational change. Yönetim, 15(47), 3-14.

Genç, S.Z., \& Eryaman, M.Y. (2012). Changing values and new education paradigm. Retrieved 12th July, 2012 from www.aku.edu.tr/AKU/DosyaYonetimi/SOSYALBILENS/.../c9s1m6.p...

Gizir, S. (2008). Organizational culture and organizational learning in organizational change proccess. Journal of Educational Faculty of Mersin University, 4(1), 182-196.

Karip, E. (1998). Transformational leadership. Retrieved 12th July, 2012 from http://www.pegem.net/akademi/3-822Donusumcu-Liderlik.aspx

Kocabaş, F. (2012). The necessity for the integration of internal and external organizational change efforts in the adaptation process to a change. Retrieved 12th July, 2012 from 
yordam.manas.kg/ekitap/pdf/Manasdergi/sbd/sbd13/sbd-13-22.pdf

Korkmaz, M. (2008). A quantitative study on the relation between the leadership types of the school managers and the characteristics of a learning organization. Education Management in Theory and Application, 53, 75-98.

Lakomski, G. (2001). Organizational change, leadership and learning: culture as cognitive process. International Journal of Educational Management, 15(2), 68-77. http://dx.doi.org/10.1108/09513540110383791

Olkun, S. (1995). Management of organizational change: organizational culture and leadership factor. Education Management, 2(4), 565-574.

Öneren, M. (2008). Learning Organizations Approach in Companies. ZKU Journal of Social Science, 4(7), 163-178.

Özgener, Ş., \& Kılıç, G. (2009). The leadership types in educational institutions and the effect of organizational culture on performance. National Management and Organization Congress XVII, Eskişehir Osmangazi University, Faculty of Economics and Administrative Sciences, Eskişehir.

Saylı, H., \& Tüfekçi, A. (2008). The role of a transformational leader in making a successful organizational change. Erciyes University, Journal of Economics and Administrative Sciences Faculty, 30, 193-210.

Tichy, N.M., \& Ulrich, D.O. (2008). Transformational Leadership. Retrieved 12th July, 2012 from userwww.sfsu.edu/ npagan/.../leadership.p

Toker, K. (2007). Organizational change and an application on textile companies in Çorlu Çerkezköy Region. Unpublished Master's thesis. Institute of Social Sciences at Trakya University, Edirne.

Töremen, F. (2002). The hindrances for change in education organizations and their reasons. Journal of Social Sciences Furat University, 12(1), 185-202.

Tunçer, P. (2011). Organizational change and leadership. Journal of Court of Accounts, 80, 57-83.

Turan, Ş. (2011). Organizational Cynism as an influential factor of organizational Change During Globalisation and A study on State Institutions in Karaman city. Unpublished Master's Thesis, Institute of Social Sciences at Karamanoğlu Mehmet Bey University, Karaman. 